\section{PRECISE CUTTING POWER}

NSK recently asked over 50 users of their VarioSurg ultrasonic surgical system why they used the system and what practical benefits it delivers.

VarioSurg users sited numerous benefits including the bright LED handpiece, which illuminates the operating field very clearly and, unlike some other machines, does not get hot with prolonged usage. Users also appreciated the efficient, gentle bone cutting delivered by the VarioSurg in comparison to drills - as the patient experiences much less pain and swelling in the post-op period - and that the incidence of complications is very low. Additionally users said the display was intuitive to use and very easy to navigate during surgery.

Users reported that the NSK VarioSurg delivers strong, precise cutting power and an ultrasonic approach to surgery that reduces heat generation and minimises osteonecrosis. This is enhanced by TiN (Titanium Nitride) coated bone cutting tips, increasing cutting efficiency and leaving a sharp surface that aids bone formation.

The NSK VarioSurg and most of the NSK product range is available to clinicians on a 'Try before you buy' basis. For more information call 0800 6341909 or visit www.nsk-uk.com.

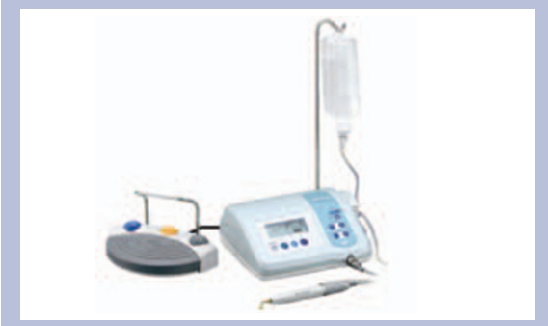

\section{A WIDE RANGE OF BENEFITS}

Studies show that the Waterpik Water Flosser it is up to two times more effective than string floss at improving gingival health.

In a recent survey, dentists were asked the main reason for recommending the Waterpik Water Flosser. Their top responses were that it accesses areas that a toothbrush cannot reach; that

\title{
FLOODLIGHTS FOR THE ORAL CAVITY
}

The recently revealed A-dec LED dental operatory light is now available to dentists around the world.

A-dec's advanced light emitting diode (LED) technology has been optically engineered specifically for dentists. The A-dec LED stands alone in the market because of how well it reduces eye strain and provides optimal ergonomics while ensuring ample illumination, clarity and depth during treatment.

The LED light features multiple intensity levels of 15,000 lux, 25,000 lux and 30,000 lux at 5,000K, flooding the oral cavity with a consistently neutral white light for true-to-life tones, helping dentists diagnose clearly. The light's cure-safe mode emits a brilliant yellow light at 25,000 lux, enabling the dental team to work effectively without curing photoinitiated resins.

The light's 'stadium effect' mitigates shadows and maintains a uniform

\section{NEW NHS PRACTICE FOR MANCHESTER}

Boots UK has launched a new dental surgery providing NHS services, located within one of its largest stores on Market Street, Manchester. This is the second dental surgery to open in a Boots UK store and complements the store's existing healthcare offer of pharmacy services, Boots Opticians, David Omerod Hearingcare and a GP Walk-in Centre provided by Go to Doc.

Ocean Dental will offer a full range of NHS services, modern light pattern, plus, its unencumbered controls, unparalleled positionability, and fluid movement, combine to create outstanding ergonomics.

This latest addition sets a premium standard for A-dec Dental Lights, a family of lighting solutions that also include the A-dec 500 Halogen 3-Axis and A-dec 300 Halogen 2-Axis.

www.a-dec.co.uk

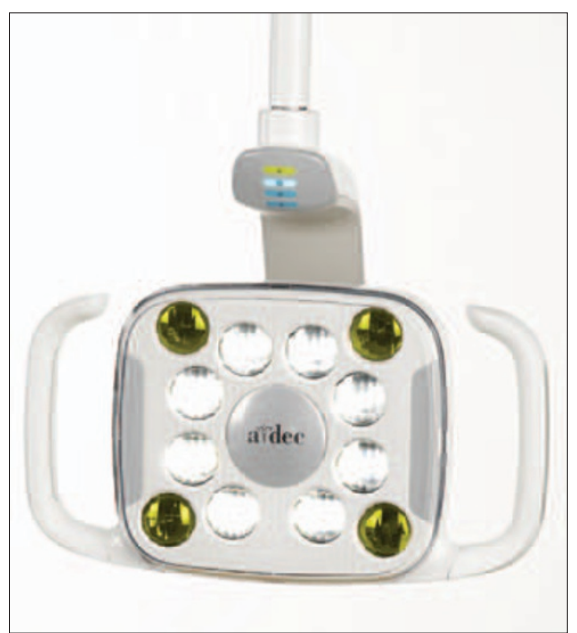

facilities and a private treatment room. The dental surgery will serve approximately 9,000 patients in the local area. The new NHS dental practice is located on the 2 nd floor of the Boots UK store and will be open Monday to Saturday, 9am to $6 \mathrm{pm}$. The dental surgery is part of Boots UK's strategy to provide active care in the local community. Boots health experts can advise customers on their wellbeing as well as the treatment of health conditions.

New patients can register at the practice by ringing 0161660 0200, or email odental@hotmail.co.uk. 